\title{
Didática da História: uma leitura teórica sobre a História na prática
}

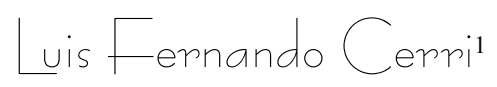

O fenômeno social do ensino de História surge no contexto da construção deliberada de identidade nacional, durante o processo de construção da soberania popular, em detrimento da soberania real. Mesmo no caso do Brasil, em que a História pesquisada e ensinada se constitui no seio do Império, é da produção de brasileiros que se trata, ligados ao poder do monarca na medida em que ele expressa a própria nação. Numa monarquia constitucional, a História não deixa de ser o produto liberal e iluminista, a exemplo do que se passa em alguns países europeus do século XIX. Esta marca de nascença da sociedade em que primeiro se inseriu vai caracterizar, em maior ou menor grau, o ensino de História até a atualidade. Com um pouco mais de pesquisa e de História comparada pode-se dizer que o ensino de História não é um fato homogêneo e de igual significado nos diferentes países em que se insere. No Brasil, o surgimento em uma sociedade escravista e aristocrática criará uma espécie de "código genético" dificilmente combatido ao longo de tantos anos: esse código - que poderíamos chamar, junto com Cuesta Fernandez ${ }^{2}$ - de código disciplinar, é caracterizado,

\footnotetext{
${ }^{1}$ Doutor em Educação pela Universidade Estadual de Campinas. Professor do Departamento de História e do Programa de Pós-Graduação em Educação da UEPG.

${ }^{2}$ Citado por Amézola, que descreve o conceito de código disciplinar como "o conjunto de ideias, valores, suposições, regulamentações e rotinas práticas, de caráter expresso e tácito) que se traduzem em discursos legitimadores e linguagens públicas sobre o valor educativo da História, e que orientam a prática profissional dos docentes. Em suma, o elenco de ideias, discursos e práticas dominantes no ensino de História dentro do marco escolar." (AMÉZOLA, Gonzalo Álvaro. Esquizohistoria. La Historia que se enseña en la escuela, la que preocupa a los histo- 
no Brasil das transições "pacíficas" e pelo alto, pela busca de uma identidade assimiladora, unificadora, colaboracionista, ao contrário de identidades mobilizadoras, por exemplo, para a guerra. Esse seria o caso, por exemplo, de França e Alemanha, elaborando seus códigos disciplinares no contexto do conflito militar e da disputa diplomática pela Alsácia-Lorena. ${ }^{3} \mathrm{O}$ ensino de História participa, portanto, como instrumento, da construção de identidades que são ao mesmo tempo de solidariedade e de assassínio. Em outras palavras, ou o amor à pátria e o compromisso com os concidadãos se articula mais ou menos explicitamente à disposição de matar e morrer pela pátria. O nacionalismo coloca a nação como valor supremo, acima da vida, e talvez abaixo apenas de Deus.

O que se espera socialmente do ensino de História? Espera-se que ela forneça um conjunto de conhecimentos mais ou menos fragmentários cujo domínio deveria ser obrigação de todo cidadão. Assim, determinadas coisas, acontecimentos e pessoas, se bem compreendidas e guardadas - o que envolve também um elemento afetivo - propiciariam ou ajudariam a propiciar um bom cidadão, comprometido com os objetivos de sua pátria. No nascedouro, a História funciona, sobretudo para a República, como uma espécie de religião cívica que substitui - na Franca revolucionária ${ }^{4}$ - ou se emparelha - no caso da república brasileira ${ }^{5}$ - as festas do calendário litúrgico e a hagiografia católica. Assim, uma determinada visão do ensino da História, que hoje tomamos como simplista, espera que este leve o aluno- cidadão a saber as orações civicas - os hinos - e os nomes dos principais santos cívicos, os próceres. Mais especializadamente, esperase que o ensino de História contribua de modo decisivo para a formação do cidadão em nossas sociedades, colaborando

riadores y una renovación posible de la historia escolar. Buenos Aires: Libros del Zorzal, 2008, p. 18)

3 CITRON, Suzanne. Le Mythe Nacional. Paris, Ed. Ouvriéres, 1987, p. 18.

${ }^{4}$ OZOUF, Mona. La fête Revolutionaire - 1789-1799. Paris, Gallimard, 1976.

${ }^{5}$ CARVAlHO, José Murilo. A Formação das Almas. São Paulo: Cia. das Letras, 1990 
para o surgimento e consolidação do espírito público, do patriotismo e do respeito aos interesses e projetos coletivos, por meio da vinculação de todos a um passado comum.

Entre vários pesquisadores, Christian Laville duvida que o ensino de História continue tendo essa importância ou sendo capaz de promover a formação sólida dessas atitudes. Parte do motivo está no fato de que até as atitudes cívicas não são mais as que se esperava do cidadão de meados do século XX ${ }^{6}$. Se a História ensinada não mais é o locus privilegiado da formação do cidadão - (será que um dia já foi?) - aprende-se em outras instâncias e de outras maneiras, que não formalmente e/ou na escola. Essa consciência é um dos fatores que ajudam a deslocar o papel e o perfil da Didática da História na contemporaneidade.

Há uma crise atual do ensino de História que periste no Cone Sul. Com o fim das ditaduras militares, não se admite mais que o ensino de História continue sustentado na Doutrina da Segurança Nacional, que aliás havia se apropriado muito eficazmente dos esquemas de produção ideológica e afetiva de civismo, dentro da sua versão escola,. Superadas as ditaduras, a crise de identidade social que se manifesta no ensino de História pode ser traduzida na seguinte pergunta: qual indivíduo queremos formar, para qual projeto de nação? A recolocação - muitas vezes descontínua e atabalhoada - da questão do projeto nacional, também deixa em fragmentos os projetos de ensino de História. Os projetos públicos mais avisados para o ensino começam a fazer da individualidade, da autonomia pessoal e da identidade fragmentada em subgrupos a única alternativa aparentemente honesta de identidade para a qual o ensino de História poderia apontar, quando buscasse fugir do autoritarismo, da manipulação, da imposição artificial de um padrão de comportamento coletivo.

Em pinceladas muito gerais, esse é o contexto em que nos atrevemos a falar sobre o papel que a aprendizagem da História pode ter. Já de saída, definimos que não podemos

\footnotetext{
${ }^{6}$ LAVILLE, Christian. A guerra das narrativas. Revista Brasileira de História. São Paulo, v. 19, nº 38, p. 125-138. 1999. 
falar mais em ensino escolar de História como uma variável independente e capaz de equacionar sozinha a questão das aprendizagens históricas. A história não - escolar, não formal, é um fator no centro das preocupações e análises, se não queremos continuar num esforço inócuo de entender e intervir no que vemos e ouvimos. Nessa quadro, como formar "autenticamente", sem manipulações ou imposições de visões de mundo prévias, a identidade do aluno, se não enxergamos mais a possibilidade de uma identidade global, sobreposta a todas as outras, como foi o caso da identidade nacional? Por certo, o nacionalismo continua tendo o seu papel, mas no presente momento ele não tem aquele apelo superior e transcendente: mistura-se e nivela-se a outras demandas por sentido do tempo e de identidade.

Quem seria o bom cidadão, o modelo ao qual os professores de história, as escolas e os movimentos deveriam dirigir seus esforços? Decerto não é mais aquele que apoia os governos, entendendo-os como encarnação da nacionalidade. Pelo contrário, ir contra os governos não raro é um ato de civismo, mesmo com tantos governos colando sua imagem à ideia da própria nação. Como formar esse civismo, se não podemos ignorar a crítica social e histórica às mazelas e dilacerações da história nacional? Como assumir a identidade nacional, como se amar o país, se não ocultamos todos os dramas, desonestidades e violências que estão presentes até hoje, enterradas junto com os alicerces nacionais? É possivel formar um cidadão útil à sua pátria e à humanidade se ele não encontra nenhum elo intelectual e afetivo que permita constituir identidade? Como é que se ensina e aprende a amar a nação e, ao mesmo tempo, forma-se um cidadão que seja informado, crítico, questionador, portador da dúvida e da desconfiança que formam o senso crítico? Como se confia desconfiando na "comunidade de destino" (nos dizeres de Otto Bauer sobre a nação), de modo a manter a distância mínima necessária para conseguir fazer contínuas análises criticas?

Quando trabalhamos a partir do conceito de consciência histórica, essas questões são naturais. Em primeiro 
lugar, porque recolocam o ensino escolar de História na sua dimensão real, mergulhado na vida da sociedade que o produz. A consciência história pode ser definida como "a suma das operações mentais com as quais os homens interpretam a sua experiência de evolução temporal de seu mundo e de si mesmos, de tal forma que possam orientar, intencionalmente, sua vida prática no tempo" 7 ou ainda "o grau de consciência da relação entre o passado, o presente e o futuro" 8 (ver ilustração 1).

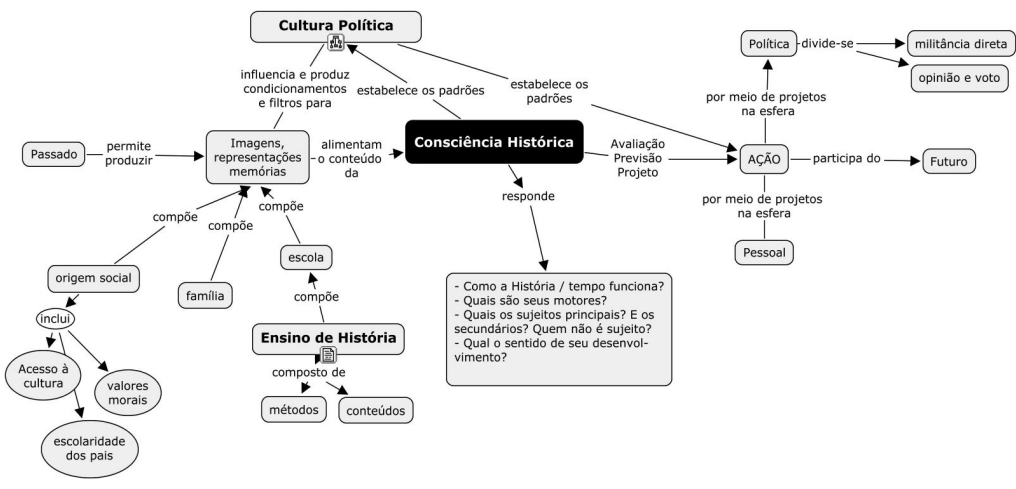

Do conceito de consciência histórica decorrem algumas consequências importantes, sobre a teoria da história e sobre o ensino. Com esse conceito, a Didática da História não pode ser mais o conjunto de teorias e métodos voltados ao ensino, mas precisa ser uma teoria da aprendizagem histórica, superando, se quiser responder aos desafios contemporâneos, o campo restrito da metodologia de ensino ${ }^{9}$.

\footnotetext{
${ }^{7}$ RÜSEN, Jörn. Razão Histórica - Teoria da História: os fundamentos da ciência Histórica. Trad. Estevão de Rezende Martins. Brasília: Editora da UnB, 2001, p. 57.

${ }^{8}$ ANGVIK, Magne e BORRIES, Bodo von (eds.) Youth and History. A comparative european survey on historical consciousness and political attitudes among adolescents. Hambourg: Edition Körber-Stiftung, 1997. Vol. A., p. 403.

${ }^{9}$ RÜSEN, Jörn. História viva. Teoria da História III: formas e funções do conhecimento histórico. Trad. Estevão de Rezende Martins. Brasília: Editora da Universidade de Brasilia, 2007, p. 88-94. 


\section{Consequências do conceito de consciência histórica para \\ o ensino}

O conceito de consciência histórica conduz à compreensão mais sistematizada de que não se espera pela escola para ter orientação temporal. Se precisamos estabelecer mesmo que sempre de modo provisório - um sentido do tempo, de modo a nos posicionarmos nele e tomarmos nossas decisões, nossa coleta e organização de dados e conceitos sobre o tempo surge praticamente junto com a consciência de si. E as fontes do saber histórico variam e podem diferir muito em relação ao que se aprende na escola, a começar pelos próprios modelos de tempo e de passado apreendidos a partir da própria experiência de vida. Segundo Peter Lee ${ }^{10}$, um dos problemas é que os alunos percebem o passado como permanente, ou seja, em nenhum momento se perguntam "como sabemos", mas veem a história verdadeira, dada, pronta. Seu modelo de passado tende a restringir-se à sua memória, que envolve um tempo muito pequeno; por isso, tendem a não conseguir compreender um maior afastamento temporal e encaixar o que aprendem em História no seu modelo limitado de passado a partir da própria experiência de vida.

O modelo de conhecimento dos alunos em idade escolar é, na maior parte dos casos, empírico, ou seja, a possibilidade do conhecimento se dá desde que possamos ver ou experimentar de algum modo as coisas; o conhecimento é uma função da experiência. Isso dificulta a ideia de relatividade dos pontos de vista, já que as visões só podem ser, nesse modelo, verdadeiras ou falsas, e no limite, se não podemos experimentar algo diretamente, o conhecimento é impossivel. Em geral, a consciência histórica do aluno está condicionada pela ideia de que a história conta "o que aconteceu"; então, se aconteceu, não há o que questionar. Por isso, as afirma-

${ }^{10}$ LEE, Peter. Em direção a um conceito de literacia histórica. Educar. Número Especial, p. 131-150, 2006. 
ções possivieis tendem a ser aquelas que cabem na realidade que os alunos conhecem. Lee conclui:

A compreensão de como as afirmações históricas podem ser feitas, e das diferentes formas nas quais elas possam ser mantidas ou desafiadas, é uma condição necessária para a literacia histórica, mas não suficiente. Se os alunos que terminam a escola são capazes de usar o passado para ajudá-los a atribuir sentido ao presente e ao futuro, eles devem levar consigo alguma história substantiva. O problema parece ser menos com nosso entendimento de como construir o conhecimento profundo dos estudantes do que com nossa habilidade de fornecer a eles um grande quadro ${ }^{11}$.

A perspectiva de uma literacia histórica - ou, no uso mais comum no português brasileiro - de um letramento histórico é um marco decisivo, pois supera a ideia de ensino de História como transmissão, rumo a ideia de um saber que só concretiza a sua necessidade se é aplicável e faz diferença na capacidade do sujeito de agir no mundo em sintonia com sua progressiva leitura desse mesmo mundo.

Nesse quadro, o ensino de história pode ser definido como a interferência de caráter de desenvolvimento cognitivo, capaz de ajudar o aluno a abrir novas portas para a sua capacidade de pensar, definir e atribuir sentido ao tempo. Constitui-se, assim, como esforço de orientação ou reorientação das formas de produção de sentido dos outros, a ser regulado cientifica e socialmente, evitando abusos políticos, bem como neutralismos esterelizantes.

A formação da consciência histórica é fenômeno social com múltiplos elementos e variáveis. Ao considerar o conceito, dimensiona-se o efetivo papel da disciplina de história na escola, ou seja, o de um dos fatores intervenientes nesse fenômeno. Assim, a Didática da História passa a exigir um redimensionamento, também, dos objetivos disciplinares, deixando para trás as listas de conteúdos como centro do debate. Esse centro passa a ser a preocupação com a identidade de quem receberá a ação do professor de história. Num contexto de crise de todos os grandes sistemas explicativos

\footnotetext{
${ }^{11}$ LEE, op. cit., p. 140.

270 Revista de História Regional 15(2): 264-278, Inverno, 2010
} 
do tempo e que têm a pretensão de definir os destinos das pessoas, os objetivos do ensino deslocam-se para promoção de identidades que possam ser refletidas e assumidas seletiva e criticamente pelo sujeito, em vez de impostas desde fora. Em outros termos, os objetivos do ensino deslocam-se para a promoção de identidades com maior autonomia, bem como para a prevenção de identidades não-razoáveis. Segundo Habermas, citado por Garcia ${ }^{12}$, a questão é se as sociedades complexas podem estabelecer identidades razoáveis, ou seja, sustentáveis do ponto de vista de uma razão comunicativa. As identidades não razoáveis seriam marcadas por uma radicalização do que é, na essência, toda identidade: delimitar e excluir. São, portanto, destrutivas e / ou autodestrutivas. Quando uma identidade implica a negação da humanidade, dos direitos e da vida das outras identidades, temos uma identidade não razoável que precisa ser prevenida, para o bem da coletividade. Mas isso não passa por negar a necessidade básica de estabelecer identidades, nem por impor um padrão único a elas, já que, em alguma medida, todos os pertencimentos têm algum grau de ficção, estética e afetividade, que não excluem necessariamente a racionalidade, e sem o que nenhuma identidade seria suficientemente atrativa ou interessante para sobreviver.

Nesta situação de ambivalência, é uma das exigências da Didática da História que o ensino de História tenha que ser o lugar onde se reflita de maneira critica sobre as identidades próprias e alheias. A necessidade de uma atitude autocrítica é tanto mais urgente quanto o ensino da história mesmo faz parte da cultura histórica de uma sociedade; além disso, 'culturas são ofertas de identidades' (A. Assmann) e por onde o ensino de história se coloca dentro destas ofertas. ${ }^{13}$

Outra consequência da consciência histórica para o ensino é reforçar o princípio - sempre enunciado, mas nem sempre levado a sério - de que o trabalho didático com a

\footnotetext{
${ }^{12}$ GARCIA, Verena R. Aprendizaje histórico: algunas consideraciones e propuestas didacticas desde una óptica alemana. In: SILLER e GARCIA (coords.). Identidad en el imaginario nacional. Reescritura y enseñanza de la historia. Puebla: BUAP, 1998, p. 288.

${ }^{13}$ Idem, p. 289. Tradução do autor.
} 
história não se resume ao passado, mas deve articular passado, presente e futuro. É assim que funciona a consciência histórica, e se o ensino de história pode ser redefinido como o esforço por uma intervenção racionalizante e humanista sobre aquela consciência, então é assim que devemos agir. Mais que um recurso para mobilizar a atenção dos alunos, a articulação do passado com o presente e o futuro no ensino segue as características estruturais do pensamento das pessoas. Isso recoloca a importância de pensar a partir do presente, e de recolocar o tema do futuro como um tema da história, tanto no passado quanto no presente. Estamos falando, claro, de projetos e de utopia. Interferir sobre a consciência histórica significa interferir sobre as identidades, e elas não são feitas somente de bases de passado comum, mas também de pretensões, objetivos e sonhos.

$\mathrm{O}$ conceito de consciência histórica também reforça o objetivo da disciplina em retirar os jovens da perspectiva de um presente fora do tempo em que se encontram imersos. Segundo Eric Hobsbawn: "Quase todos os jovens de hoje crescem numa espécie de presente contínuo, sem qualquer relação orgânica com o passado da época em que vivem." ${ }^{14}$.

O modelo de razão ao qual Rüsen se filia abre margem para articular a perspectiva de conscientização histórica - ou seja, a ação dos historiadores e professores sobre a consciência histórica dos alunos - com a perspectiva de conscientização em Paulo Freire. Para ele, conscientizar é movimento dialógico e bilateral, não a doação unilateral de consciência de quem tem para quem não tem. Essa postura, ao mesmo tempo teórica e política, assume a consciência histórica como uma constante antropológica, ou seja, não há quem tenha e quem não tenha consciência histórica, nem há consciência que seja em si melhor que outra. O que há são diferenças e diferentes adequações dos modos de geração de sentido (tradicional, exemplar, crítico e genético) às conjunturas mutantes de cada tempo. Além disso, o objetivo educacional do en-

\footnotetext{
${ }^{14}$ HOBSBAWN, Eric. A era dos extremos. O Breve Século XX: 1914 - 1991. São Paulo: Companhia das Letras, 1995, p. 13. 
sino de história não está em fazer evoluir o pensamento das formas mais simples para as mais sofisticadas de atribuição de sentido ao tempo, ou tornar uma consciência, por exemplo, "crítica" ou "genética". Porque esses modos não existem puros na realidade, são tipos ideais. Não existe consciência que se defina por algum dos modos de geração de sentido. $O$ que ocorre é que não se pode ou não se deveria determinar sozinho e imperativamente os interesses e as necessidades de orientação temporal dos outros. Paulo Freire é esclarecedor quanto a isso em "A importância do ato de ler":

Cada um de nós é um ser no mundo, com o mundo e com os outros. Viver ou encarnar esta constatação evidente, enquanto educador ou educadora, significa reconhecer nos outros - não importa se alfabetizandos ou participantes de cursos universitários; se alunos de escolas do primeiro grau ou se membros de uma assembléia popular - o direito de dizer a sua palavra. Direito deles de falar a que corresponde o nosso dever de escutá-los. De escutá-los corretamente, com a convicção de quem cumpre um dever e não com a malícia de quem faz um favor para receber muito mais em troca. Mas, como escutar implica falar também, ao dever de escutá-los corresponde o direito que igualmente temos de falar a eles. Escutá-los no sentido acima referido é, no fundo, falar com eles, enquanto simplesmente falar a eles seria uma forma de não ouvi-los. Dizer-lhes sempre a nossa palavra, sem jamais nos expormos e nos oferecermos à deles, arrogantemente convencidos de que estamos aqui para salvá-los, é uma boa maneira que temos de afirmar o nosso elitismo, sempre autoritário. Este não pode ser o modo de atuar de uma educadora ou de um educador cuja opção é libertadora ${ }^{15}$.

O que pode e deve existir, sim, é algo como a "tomada de consciência", tal como figura na teoria de Piaget, pela qual o sujeito completa um ciclo de seu processo de aprendizagem ao conseguir reconhecer o caminho cognitivo que fez para chegar ao seu estado de conhecimento, ou, em outras palavras, a autoconsciência dos próprios mecanismos de pensamento / cognição. De qualquer modo, não é algo que possa vir de fora, que possa ser dado ou passado, mas o resultado de um esforço, de uma caminhada do próprio sujeito.

${ }^{15}$ FREIRE, Paulo. Importância do ato de ler: em três artigos que se completam. 23. ed. São Paulo: Autores Associados: Cortez, 1989, p. 17. 
Se por um lado não é apropriado tomar a consciência histórica como objetivo de ensino, já que se trata de um conceito cuja principal função é heurística, por outro lado certamente decorre desse conceito um objetivo de ensino. Trata-se da ideia de competência narrativa. Em Rüsen, a competência narrativa é a competência específica e essencial da consciência histórica, uma vez que é através da narrativa que se pode realizar a orientação temporal, sintetizando historicamente as dimensões do tempo, do valor e da experiência ${ }^{16}$. Em outros termos, consiste "na faculdade de representar o passado de modo tão claro e descritivo que a atualidade se converta em algo compreensível e que a própria experiência vital adquira perspectivas de futuro sólidas" ${ }^{17}$. Não se trata de competência no sentido de uma habilitação acadêmica, a qual se atingiria por meio de algum curso e se resolveria o problema de modo definitivo. Como capacidade de atribuição de sentido histórico, de organização temporal da orientação da vida prática e de interpretação de si e do mundo ${ }^{18}$, resulta de um aprendizado, e se reconstrói continuamente, em função das novas experiências e mudanças na realidade e do diálogo com novos argumentos. A incompetência narrativa, por consequência, é a incapacidade de orientar-se no tempo de acordo com a própria identidade, dialogando com o conjunto de elementos históricos intervenientes na vida prática e o conjunto de ideias e argumentos presentes no mundo cultural. Novamente, vemos a aproximação dos postulados que sustentam a Didática da História com as proposições habermasianas da ação comunicativa, assim como com as proposições freirianas de uma epistemologia dialógica.

As subdivisões propostas para a competência narrativa são: a competência de experiência ou perceptiva, que é

\footnotetext{
${ }^{16}$ RÜSEN, Jörn. El desarollo de la competencia narrativa en el aprendizaje histórico. Una hipótesis ontogenética relativa a la consciencia moral. Propuesta Educativa. Buenos Aires, n. 7, 1992, p. 29.

${ }^{17}$ RÜSEN, Jörn. A história entre a modernidade e a pós-modernidade. História: Questões e Debates. Curitiba, v. 14, n. 26/27, p. 80 - 101, jan./dez. 1997. Barcelona, n. 12, p. 79-92, abr. 1997.

${ }^{18}$ RÜSEN, op. cit., 2008, p. 103-104.

274 Revista de História Regional 15(2): 264-278, Inverno, 2010
} 
constituída pela capacidade de perceber o passado como tal, distinto e distante do presente, mas condicionante da vida; a competência interpretativa, que tem caráter teórico e vem a ser a capacidade de interpretar o que se aprendeu do passado através de sentido e significado que reconstruímos continuamente; e a competência de orientação, que tem caráter prático, uma espécie de letramento histórico, ou seja, a capacidade de aplicar as ideias e conhecimentos que produzimos reflexivamente para orientar nossa vida prática, na tomada de decisões cotidianas.

A competência narrativa faz decorrer, para o ensino, a perspectiva presente também na proposição freiriana, ao dirigir-se à alfabetização: o objetivo não se resume em ler as palavras, mas em ler o mundo. No nosso caso, o mundo no tempo.

Rüsen adiciona, à reflexão sobre o significado e a relação entre conhecimento histórico e vida prática (decisões pessoais ou coletivas sobre um determinado curso de ação), a reflexão sobre os valores morais que estão na base dos sentidos que se atribui à história e à ação, o que traz dois elementos a reter para a nossa discussão sobre o valor educativo da História: a História ensinada, derivada da história vivida na prática e da História teorizada e disciplinarizada, está construída com os materiais da reflexão sobre os interesses e os valores, e está constantemente colocando em atenção o fato de que as escolhas que afetam o curso da história são dependentes dos valores. Além disso, valores e aproximações afetivas constituem um aspecto indispensável da aprendizagem histórica, que precisa lidar, inclusive, com ficções e algum nível de suspensão do juízo crítico estrito ${ }^{19}$, sem a qual não é possivel pensar em ação no mundo, mas cujo controle é necessário para não se perder o contato com a realidade e, portanto, a competência narrativa. Sem valores, por exemplo, que são a um tempo escolhas e imposições, razão e afeto, o que pode valer o aprendizado em História?

${ }^{19}$ GARCIA, op. cit., 1998, p. 285. Tradução do autor. 
Luiz Fernado Cerri

Conforme Rüsen, novamente:

[a História] é uma tradução do passado ao presente, uma interpretação da realidade passada via uma concepção da mudança temporal que abarca o passado, o presente e a expectativa de acontecimentos futuros. Essa concepção amolda os valores morais a um 'corpo temporal'(por exemplo, o corpo da validade contínua de um antigo tratado), a história reveste os valores de experiência temporal. A consciência histórica transforma os valores morais em totalidade temporais: tradições, conceitos de desenvolvimento ou outras formas de compreensão do tempo. Os valores e as experiências estão mediatizadas e sintetizadas em tais concepções de mudança temporal." (...) "A consciência histórica amalgama "ser" e "dever" em uma narrativa significante que refere acontecimentos passados com o objetivo de fazer intelegivel ao presente, e conferir uma perspectiva futura a essa atividade atual. Desta forma, a consciência histórica faz uma contribuição essencial à consciência ética moral". ${ }^{20}$

Por fim, é preciso mencionar que o conceito de consciência histórica implica a existência na Didática da História, de um papel para a utopia e um papel para a alteridade como complemento obrigatório da formação de uma identidade razoável. A contribuição da História na escola não é só a compreensão da própria realidade e a formação da identidade. Nesse raciocínio fica mais fácil compreender como oportuna a Lei 10.639/2003, que institui a obrigatoriedade do estudo da História e Cultura Afro-brasileira, mesmo em comunidades, como é comum no Sul do Brasil, em que grande maioria da população é composta por descendentes de europeus. Pelo mesmo princípio, isso ajuda a conceber que é necessário também algum conhecimento de tempos afastados e povos em espaços distantes, com os quais parece que a nossa realidade não guarda relação quase nenhuma. Assim se pode promover uma identidade razoável ao evitar uma visão etnocêntrica do mundo e prevenir comportamentos excludentes, considerando que a modernização tende a colocar rapidamente em convivio multicultural as diferentes comunidades. Do mesmo modo, o estudo das culturas indígenas na Argentina, por exemplo, é importante, mesmo que essas

${ }^{20}$ RÜSEN, op. cit., 1992, p. 29. Tradução do autor.

276 Revista de História Regional 15(2): 264-278, Inverno, 2010 
populações sejam hoje tão pouco expressivas em termos de composição populacional.

O ensino a partir da alteridade é fundamental na própria elaboração de uma perspectiva do passado que considere o que não aconteceu, os projetos dos vencidos, uma História das ideias de mundo: para que não se ensine e não se aprenda que o presente tal como o conhecemos era a única possibilidade, com o que acabamos organizando o conhecimento do passado em função do presente, o que é um objetivo cognitivo central na formação da competência narrativa para a contemporaneidade. Assim, pode-se perceber que a realidade não é una, e que por ser histórica é modificável e dependente da ação humana. Sem esses dados, não se vislumbra que valha a pena agir na esfera coletiva, em vez de uma ação individualista e egoísta que, principalmente em tempos de crise ecológica, não é razoável, porque encaminha a destruição de si e dos outros.

\section{Didática da História: uma leitura teórica sobre a História na prática}

Luis Fernando Cerri

Resumo: A Didática de História vem passando, no Brasil, por uma mudança paradigmática, deslocando-se da metodologia do ensino à área interdisciplinar que, sustentada na Teoria da História, articula saberes pedagógicos e sócio-antropológicos para debruçar-se sobre o fenômeno da aprendizagem histórica e da circulação social do conhecimento histórico. Nesse texto, temos o objetivo de realizar um balanço despretensioso sobre as consequências dessa mudança de paradigma para a formação do professor e para a aprendizagem histórica escolar e extra-escolar. 
Luiz Fernado Cerri

Palavras-chave: Aprendizagem histórica; Consciência histórica; Teoria da história.

Abstract: The History Didactics in Brazil is going though a paradigmatic change. moving from the teaching methodology to the interdisciplinary area that, sustained on History Theory, articulates pedagogica and socio-antropological knowledges to devote itself to the phenomenon of historical learning and social circulation of historical knowledge. In this paper, we aim to carry out an unpretentious balance about the consequencies of this paradigmatic change to teachers' training and to formal and informal history learning.

Key words: Historical learning; Historical consciousness; History theory.

Recebido:23/06/2010

Aprovado:20/09/2010 